\title{
Analyses on the Changes of Grazing Capacity in the Three-River Headwaters Region of China under Various Climate Change Scenarios
}

\author{
Rongrong Zhang, ${ }^{1}$ Zhaohua Li, ${ }^{1}$ Yongwei Yuan, ${ }^{1}$ Zhihui Li, ${ }^{2,3}$ and Fang Yin ${ }^{2,4}$ \\ ${ }^{1}$ Faculty of Resources and Environmental Science, Hubei University, Wuhan 430062, China \\ ${ }^{2}$ Institute of Geographic Sciences and Natural Resources Research, Chinese Academy of Sciences, No. 11A, Datun Road, Anwai, \\ Beijing 100101, China \\ ${ }^{3}$ University of Chinese Academy of Sciences, Beijing 100049, China \\ ${ }^{4}$ Center for Chinese Agricultural Policy, CAS, Beijing 100101, China
}

Correspondence should be addressed to Fang Yin; yinf.10s@igsnrr.ac.cn

Received 19 May 2013; Revised 17 July 2013; Accepted 4 August 2013

Academic Editor: Xiangzheng Deng

Copyright (C) 2013 Rongrong Zhang et al. This is an open access article distributed under the Creative Commons Attribution License, which permits unrestricted use, distribution, and reproduction in any medium, provided the original work is properly cited.

\begin{abstract}
On the livestock production in the Three-River Headwaters region (TRHR) in the macrocontext of climatic change, this study analyzed the possible changing trends of the net primary productivity (NPP) of local grasslands under four RCPs scenarios (i.e., RCP2.6, RCP4.5, RCP6.0, and RCP8.5) during 2010-2030 with the model estimation, and the grass yield and theoretical grazing capacity under each scenario were further qualitatively and quantitatively analyzed. The results indicate that the grassland productivity in the TRHR will be unstable under all the four scenarios. The grassland productivity will be greatly influenced by the fluctuations of precipitation and the temperature fluctuations will also play an important role during some periods. The local grassland productivity will decrease to some degree during 2010-2020 and then will fluctuate and increase slowly during 2020-2030.The theoretical grazing capacity was analyzed in this study and calculated on the basis of the grass yield. The result indicates that the theoretical grazing capacity ranges from 4 million sheep to 5 million sheep under the four scenarios and it can provide quantitative information reference for decision making on how to determine the reasonable grazing capacity, promote the sustainable development of grasslands, and so forth.
\end{abstract}

\section{Introduction}

The net primary productivity (NPP) of vegetation reflects the productivity of the vegetation under the natural conditions [1]. The climatic change is one of the key driving forces of the interannual change of NPP of vegetation [2]. The climate is undergoing the change which is mainly characterized by the global warming. The land surface temperature has increased significantly since the 1980 s, especially in the northern region of China [3-6]. The grassland is one of the most important land use types in China, which has essential functions in the development of the animal husbandry [7]. The grassland is greatly influenced by the climatic change, and the spatiotemporal change of NPP of grasslands and the influencing mechanism of the climatic change on it have been one of the research focuses at home and abroad [8-11].
The Three-River Headwaters region (TRHR) is the headstream of the Yellow River, Yangtze River, and Lancang River, which is one of the most ecologically sensitive areas in China. Besides, it is also the largest animal husbandry production base in Qinghai Province, with about 21.3 thousand $\mathrm{km}^{2}$ of native pasture and native grassland. Many researchers have analyzed the change of NPP in this area from different perspectives [12-16] and there have been many research works on the pattern and spatiotemporal characteristics of NPP of ecosystems. However, there have been few comprehensive studies on the spatiotemporal change of NPP of grasslands and the consequent effects in the TRHR. On the one hand, owing to the distinctive natural ecological conditions in this region, the development of local animal husbandry always depends on the increase of the livestock amount, 
which increases the income of local people and meanwhile leads to the long-term overgrazing. The serious grassland degradation has greatly restrained the development of the local animal husbandry and change of landscape [17]. On the other hand, the global warming has led to the decrease of the average annual precipitation, and the grass yield per unit area also decreases slightly year by year, which has threatened the development of local animal husbandry. Therefore a description of the climate and relevant economic activities in the study area is detailed and significant [18]. In order to solve the problems brought by the grassland degradation and promote the sustainable development of the local animal husbandry in the TRHR, it is necessary to carry out scientific prediction of the local grass yield, determine the reasonable grazing capacity, and guide the production of local animal husbandry.

The research on NPP of the grassland is the basis for the study of the grass yield and prediction of grazing capacity, and there have been many investigations and research works on the estimation of NPP of the grassland in China in recent years. The methods to estimate NPP of grassland vary greatly due to the difference in the natural environment of the study area, data availability, and so forth. There are mainly four kinds of models to estimate NPP of grassland, that is, the light use efficiency model, ecosystem process model, remote sensing-process coupling model, and climatic statistic model [19]. There are both advantages and disadvantages in these models. For example, the light use efficiency model based on the mechanism of vegetation photosynthesis is easy to be constructed and has high calculation efficiency, but there are some faults in the factors taken into account, parameter selection, calculation result, and so forth. The ecosystem process model simulates the physiological processes of vegetation and applies the technologies such as the remote sensing, which makes it possible to carry out multiscale dynamic monitoring of the spatiotemporal change of NPP. However, this model is very complex and requires high quality data, which restrains its practicability to some degree, especially in the regional estimation. The remote sensing-process coupling model integrates the advantages of both the models mentioned above, but the accuracy of its calculation result is greatly influenced by other factors. The climatic statistic model introduces the regression models constructed with the simple climatic factors such as temperature and precipitation and has a low data requirement. This kind of models is more practical, but it is still limited by the low accuracy of the result. There is great complexity, uncertainties, and inaccuracy in the extraction of vegetation indices and soil parameters with the remote sensing data, all of which make it very difficult and very inaccurate to calculate these data with the light use efficiency model, ecosystem process model, and ecological remote sensing coupling model. Besides, it is a fact that the climatic conditions have great impacts on the livestock production in the study area. Therefore, the climatic statistic model was finally used to estimate the future grassland productivity in the TRHR.

The most widely used climate models mainly include the Miami Model, Thornthwaite Memorial Model, Chikugo Model, and the comprehensive model. The climate model is an effective tool in the study of climate [20]. The comprehensive model is more suitable for the estimation of NPP of vegetation in the arid area than the Chikugo Model. Besides, in comparison with other three models, the comprehensive Model has a solider theoretical foundation, takes more into account of the physiological processes of vegetation, and consequently can obtain a better estimation result in Zhejiang Province [21] and Inner Mongolia [22, 23].

In order to overall forecast the changing trend of the grassland NPP and theoretical grazing capacity in the study area in the context of climate change, four representative concentration pathways (RCPs) (which represent the emission trajectories under the natural and social conditions and the corresponding scenarios) were selected to analyze the changing trend of grassland NPP in the Three-River Headwaters region. This study is of both theoretical and practical significance. In theory, this study extends the field of application of the estimation of NPP and explored the theoretical grazing capacity in the TRHR in the future, which provides certain references for the relevant research works in other similar regions. In practice, this study qualitatively and quantitatively analyzed the changing trend of the grass yield and grazing capacity in the study area, which can provide some guidance for the local grassland utility and management and the development of animal husbandry and promote the harmonious and sustainable development of the local manland relationship.

\section{Study Area}

The TRHR is located in the southern part of Qinghai Province of China, between $31^{\circ} 39^{\prime}-36^{\circ} 12^{\prime} \mathrm{N}$ and $89^{\circ} 45^{\prime}-102^{\circ} 23^{\prime} \mathrm{E}$ with an area of 363 thousand $\mathrm{km}^{2}$ which accounts for $43 \%$ of the total area of Qinghai Province. The TRHR with the altitude ranges from $3500 \mathrm{~m}$ to $4800 \mathrm{~m}$ is the headstream of the Yellow River, Yangtze River, and Lancang River and has a dense network of rivers. The administrative regions cover 16 counties, including Yushu, Xinghai, Tongde, Zeku, Matuo, Maqin, Dari, Gande, Jiuzhi, Banma, Chengduo, Zaduo, Zhiduo, Qumalai, Nangqian, and Henan, except for Tanggula Mountain Town which is under the charge of Golmud City.

The grassland area is 203 thousand $\mathrm{km}^{2}$ in the TRHR, accounting for $65.4 \%$ of the total area of this region (Figure 1). The vegetation diversity of the TRHR is the richest among the regions at the same altitude all over the world. The grassland type changes from alpine meadow to high-cold steppe and alpine desert, with the productivity also gradually decreasing [24-27]. The grassland resource is very rich in this region; however, the grass yield per unit area has decreased year by year due to the climatic change and overgrazing in recent years, which has threatened the development of the local animal husbandry.

\section{Methodology and Data}

\subsection{Models}

3.1.1. Comprehensive Model. The comprehensive model was developed on the basis of two well-known balance 


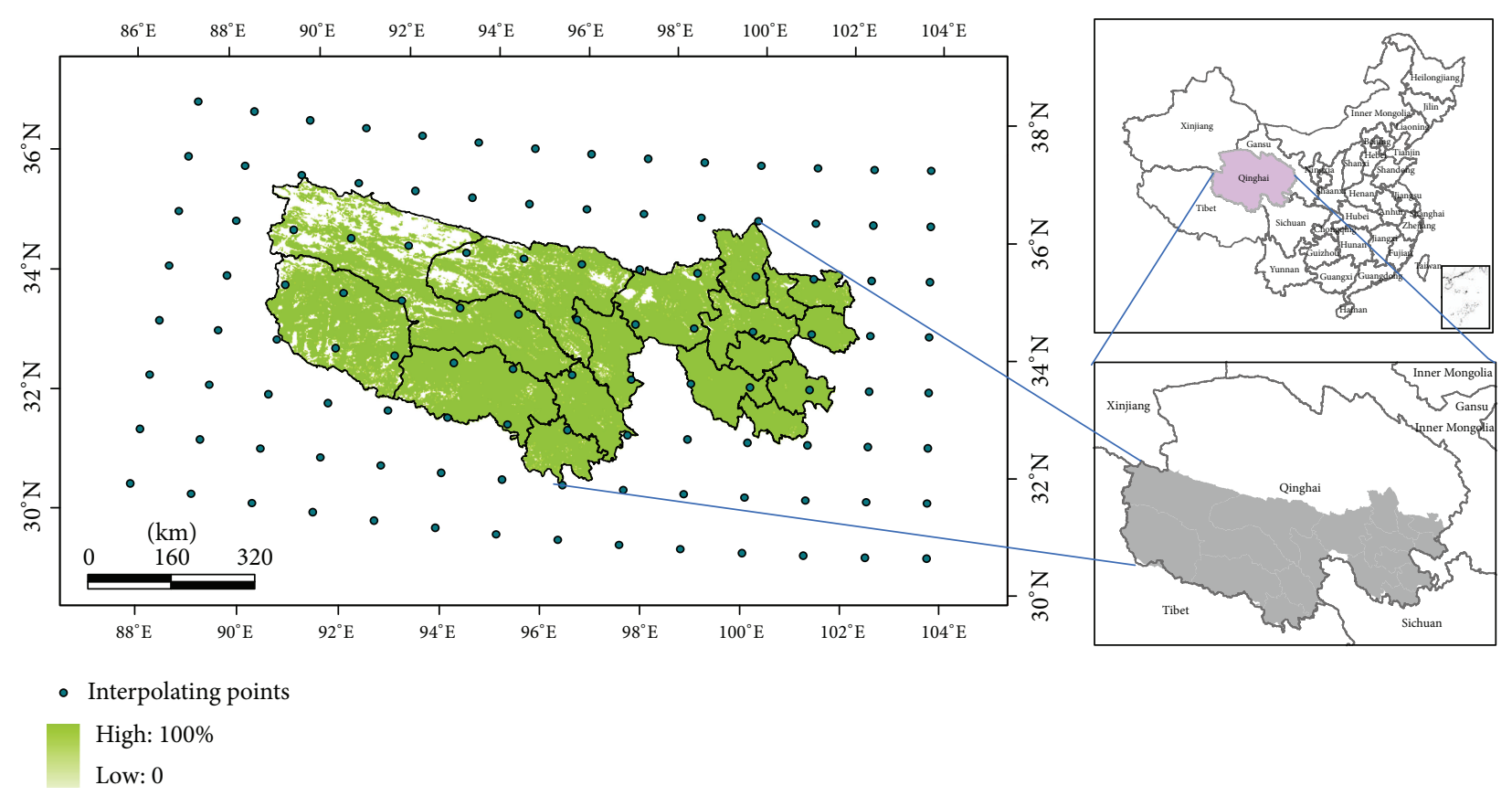

FIGURE 1: Location of the TRHR and distribution of grassland.

equations, that is, the water balance equation and heat balance equation $[28,29]$. Zhou and Zhang deduced the regional evapotranspiration model that links the water balance equation and heat balance equation from the physical process during the energy and moisture influence the vaporization and then constructed the natural vegetation NPP model based on the physiological characteristics [28, 29], that is, the Comprehensive Model. The Comprehensive Model can calculate the potential NPP of natural vegetation on the basis of the precipitation and net radiation received by the land surface in the study area. This model is of great significance to the reasonable use of climatic resource and fulfillment of the climatic potential productivity [28]. The formula of this model is as follows:

$$
\begin{gathered}
\mathrm{NPP}=\mathrm{RDI} \times \frac{P_{r} R_{n}\left(P_{r}^{2}+R_{n}^{2}+P_{r} R_{n}\right)}{\left(P_{r}+R_{n}\right)\left(P_{r}^{2}+R_{n}^{2}\right)} e^{\sqrt{9.87+6.25 \times \mathrm{RDI}}}, \\
\mathrm{RDI}=\frac{R_{n}}{L \cdot P_{r}},
\end{gathered}
$$

where $R_{n}$ is the annual net radiation, $P_{r}$ is the annual precipitation, $L$ is the annual latent heat of vaporization, and $\mathrm{RDI}$ is the radiation aridity.

3.1.2. Model of the Hay Yield of Grassland. There are mainly three indictors of the grassland productivity, that is, the hay yield, theoretical grazing capacity, and animal products [30]. The hay yield, that is, the total dry matter yield of a certain area during a certain period, reflects the primary productivity of grassland and is a basic indicator of the grassland productivity. In this study, the hay yield of grassland during 2010-2030 was calculated based on NPP of grassland with the following formula:

$$
B_{g}=\frac{\mathrm{NPP}}{S_{\mathrm{bn}}\left(1+S_{\mathrm{ug}}\right)},
$$

where $B_{g}$ is the annual total hay yield per unit area $\left(\mathrm{g} \cdot \mathrm{m}^{-2}\right.$ $\left.\cdot \mathrm{a}^{-1}\right)$, NPP is the annual total NPP of grassland $\left(\mathrm{gC} \cdot \mathrm{m}^{-2} \cdot \mathrm{a}^{-1}\right)$, $S_{\text {bn }}$ is the coefficient of the conversion coefficient of the grassland biomass and NPP $(\mathrm{g} / \mathrm{gC})$, which is $0.45[31,32]$, and $S_{\mathrm{ug}}$ is the proportionality coefficient of the over ground biomass and underground biomass, which varies among different vegetation types [33]. $S_{\mathrm{ug}}$ of the alpine meadow, high-cold steppe, and alpine desert is 7.91, 4.25, and 7.89, respectively. According to the location of the study area, $S_{\mathrm{ug}}$ of the alpine meadow was used to calculate the grass yield.

3.1.3. Model of the Theoretical Grazing Capacity of Grassland. The theoretical grazing capacity of grassland during 20102030 was calculated on the basis of the grass yield. Since the grazing capacity of grassland is customarily represented by the unit of livestock in China, that is, the number of adult livestock that can be supported by per unit of land area every year, and the number of sheep is generally used as the unit, the grazing capacity of grassland is also represented by the number of sheep per unit of land area.

There have been many methods to calculate the theoretical grazing capacity of grassland. The estimation method of "limiting livestock based on grassland carrying capacity" can better reflect the restriction of the practical situation in 
the grazing districts on the livestock production, and hence the following formula was used [34]:

$$
\mathrm{CA}=\frac{G \cdot \text { Cuse }}{U_{G} \cdot \mathrm{DOY}},
$$

where CA is the theoretical annual grazing capacity of grassland (unit: number of sheep per unit of land area), $G$ is the annual hay yield of grassland per square meter (unit: $\mathrm{kg} / \mathrm{m}^{2}$ ), and Cuse is the utilization efficiency of grass by the livestock varying among different grassland types [34]. In this study, Cuse of the alpine meadow, high-cold steppe and alpine desert, shrubbery, and swamp meadow is $60 \%, 50 \%, 40 \%$, and $55 \%$, respectively. $U_{G}$ is the hay quantity needed by per unit of sheep every day (unit: $\mathrm{kg} / \mathrm{d}$ ), which was set to be $2.0 \mathrm{~kg}$ according to the relevant criterion [35]. DOY (unit: d) is 365 . Since the grassland is the main vegetation type in the ThreeRiver Headwaters region, Cuse of the high-cold steppe was used to estimate the theoretical grazing capacity of grassland during 2010-2030.

3.2. Data Source. The data of precipitation and near-surface air temperature in the study area was simulated with the models of CMIP5 (Coupled Model Intercomparison Project Phase 5). There are three steps in the data processing. (1) The data was first selected and downloaded, including the model (CCSM4), modeling realm (atmosphere), ensemble (r6ilp1 and r5ilp1), and climatic variables (precipitation and near-surface air temperature). (2) The data of study area was then extracted and calculated. The annual average value was calculated based on the monthly data, and the annual precipitation was calculated as the sum of the monthly precipitation and then extracted 112 points covering the study area. (3) The point data with the spatial resolution $0.9 \times 1.25$ degree were interpolated in $1 \mathrm{~km} \times 1 \mathrm{~km}$ raster using the Kriging method and were projected with the Albers 1940 coordinate system.

\section{Results and Analyses}

4.1. Changing Trend of NPP of Grassland in the TRHR. There is significant spatial heterogeneity of the NPP in the TRHR, decreasing from the southeast to the northwest on the whole (Figure 2). The results indicate that the NPP of grassland mainly increases in the east and southeast part, while it decreases significantly in the northwest, southwest, and middle part. There is no significant change of the NPP of grassland in most of other parts. The changing trends of NPP during every ten years indicate that the NPP changes significantly under the RCP2.6 scenario and RCP4.5 scenario, increasing in the east and southeast part to some degree and decreasing in the south part to some extent. The NPP changes slightly under the RCP6.0 scenario and RCP8.5 scenario. Under the RCP4.5 scenario, the NPP decreases obviously in the middle and south part during 2010-2020 and increases slightly during 2020-2030, indicating that there is serious desertification of the local grassland. Besides, the increase of NPP by 2030 suggests that there is some improvement of the conditions of the local grassland.
In this study, the influence of temperature and precipitation on the change of NPP was analyzed. The result indicates that the NPP of grassland will range from $100 \mathrm{~g} \cdot \mathrm{m}^{-2} \cdot \mathrm{a}^{-1}$ to $130 \mathrm{~g} \cdot \mathrm{m}^{-2} \cdot \mathrm{a}^{-1}$ during $2010-2030$. The results under different scenarios are shown as follows (Figure 3).

The result under the RCP2.6 scenario indicates that the temperature and precipitation would present a decreasing trend during 2015-2020 and 2025-2030 and shows an opposed trend during 2010-2015 and 2020-2025 (Figure 3). The precipitation will fluctuate more greatly than the temperature on the whole. By contrast, the NPP will change in an opposite way during these periods, but with smaller amplitude of fluctuation. Therefore, there is a significant negative relationship between the NPP and temperature, while there is only a weak relationship between the NPP and precipitation under this scenario.

The result under the RCP4.5 scenario indicates that the NPP and precipitation show a similar changing trend, that is, a concave-down parabolic trajectory on the whole. The precipitation will fluctuate most greatly during 2010-2020, while the NPP first decrease with the precipitation and then increases rapidly after reaching a relatively low level. The NPP will decrease by $8.4 \%$ from 2010 to 2015, but it will increase by $8.2 \%$ from 2015 to 2020 . Then the NPP will increase slowly while fluctuating slightly during 2020-2030. Therefore, there is a significant negative relationship between the NPP and precipitation under this scenario, while the relationship between the NPP and temperature is very weak.

The result under the RCP6.0 scenario indicates that the NPP will first increase and then decrease during 2015-2025, while temperature will show an opposite changing trend during this period, as during other period they will change in a similar way. The precipitation will show an increasing trend during 2010-2015 and 2020-2030. The NPP and precipitation will both decline obviously during 2015-2020 and reach the bottom around 2020. The NPP will decrease by $10 \%$ in 2020 when compared with 2015 , which indicates that the change of NPP is greatly influenced by the change of precipitation during this period and they are strongly correlated. The result suggests that the changing trends of the NPP are consistent with those of the precipitation on the whole, but the fluctuation range of the NPP is small, indicating that there is some lag in the response of the NPP to the change of precipitation under this scenario. According to the analysis above, the NPP responds more sensitively to the change of precipitation than to the change of temperature.

Under the RCP8.5 scenario, the temperature changes slightly during 2010-2025 and 2025-2030 and shows an increasing trend during 2020-2025. Besides, the NPP also fluctuates slightly during 2010-2025 and 2025-2030, indicating that the temperature plays a dominant role in influencing the NPP. The NPP and precipitation both fluctuate significantly during 2015-2020 and there is an obvious low ebb around 2020 . The NPP decreases by $15.3 \%$ in 2020 in comparison to 2015, indicating that there is a strong correlation between the change of NPP and the change of precipitation. During 2020-2025, the NPP, temperature and precipitation all show an obvious increasing trend. The NPP increases 

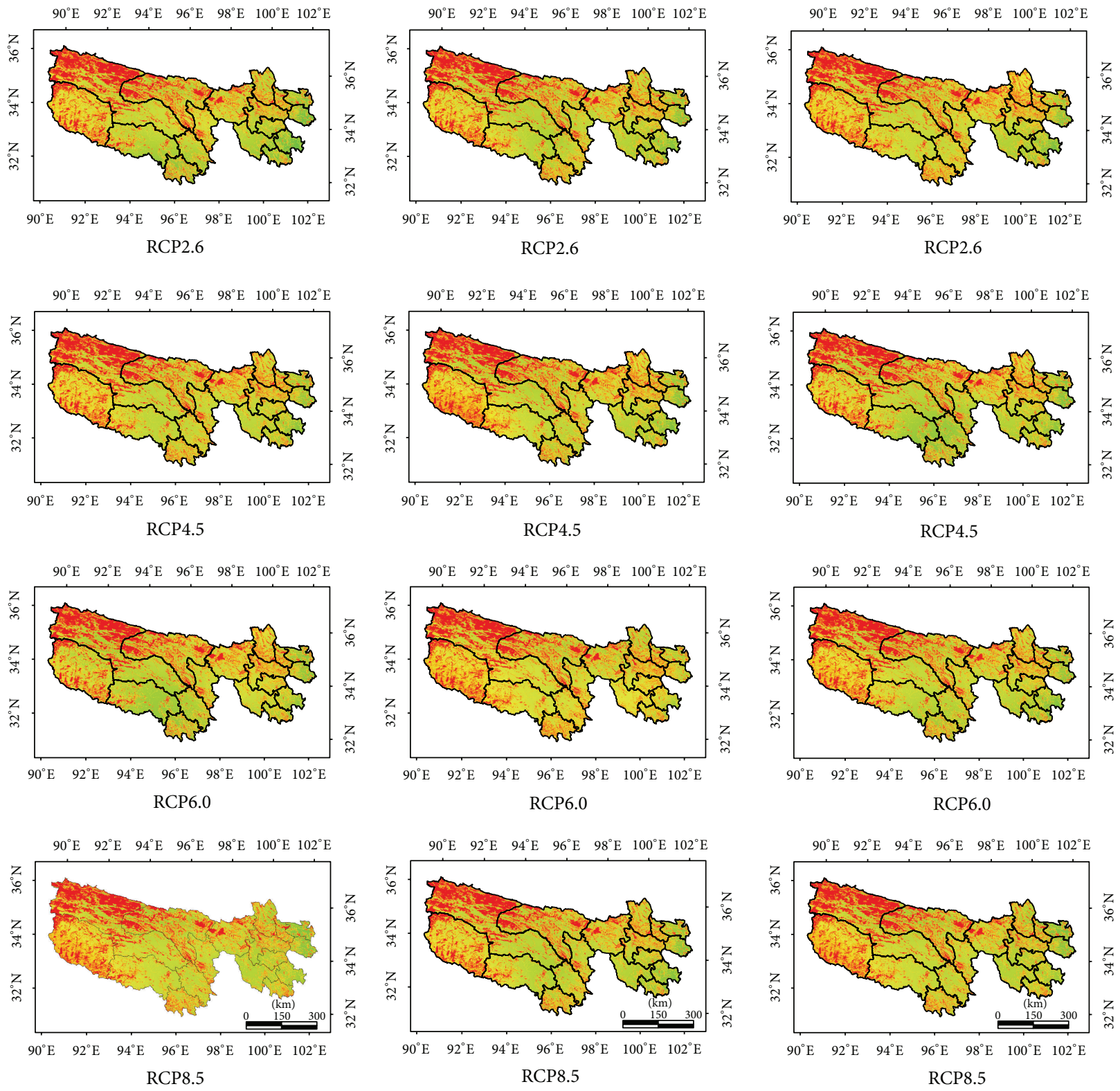

High: 260

High: 260

Low: 0

High: 260

Low: 0

FIGURE 2: The NPP map of the TRHR in 2010, 2020, and 2030 under the four RCPs scenarios.

by $20.4 \%$ from 2020 to 2025 and reaches a significant peak around 2025, indicating that there is significant relationship between the change of NPP and the changes of both the precipitation, and temperature. Therefore, the temperature plays a key role in influencing the change of NPP during 2010-2020 and 2025-2030, while the precipitation plays a dominant role during 2015-2020. Besides, during 2020-2025, both the temperature and precipitation greatly influence the NPP.

4.2. Changing Trend of Grass Yield of Grassland. The result under the RCP2.6 scenario indicates that the changing trend and fluctuation range of the grass yield are both pretty consistent with those of the NPP mentioned above; that is, both increase during 2015-2020 and 2025-2030 and decrease during 2010-2015 and 2020-2025 (Figure 4). On the whole, the grass yield is generally above 6.3 million tons under this scenario except for the period around 2025, and the fluctuation range is not great and the average yield level is very stable.

The result under the RCP4.5 scenario indicates that the grassland yield will fluctuate greatly but will still increase slightly on the whole during 2010-2015. The grass yield will keep a stable increasing trend during 2015-2030. In 

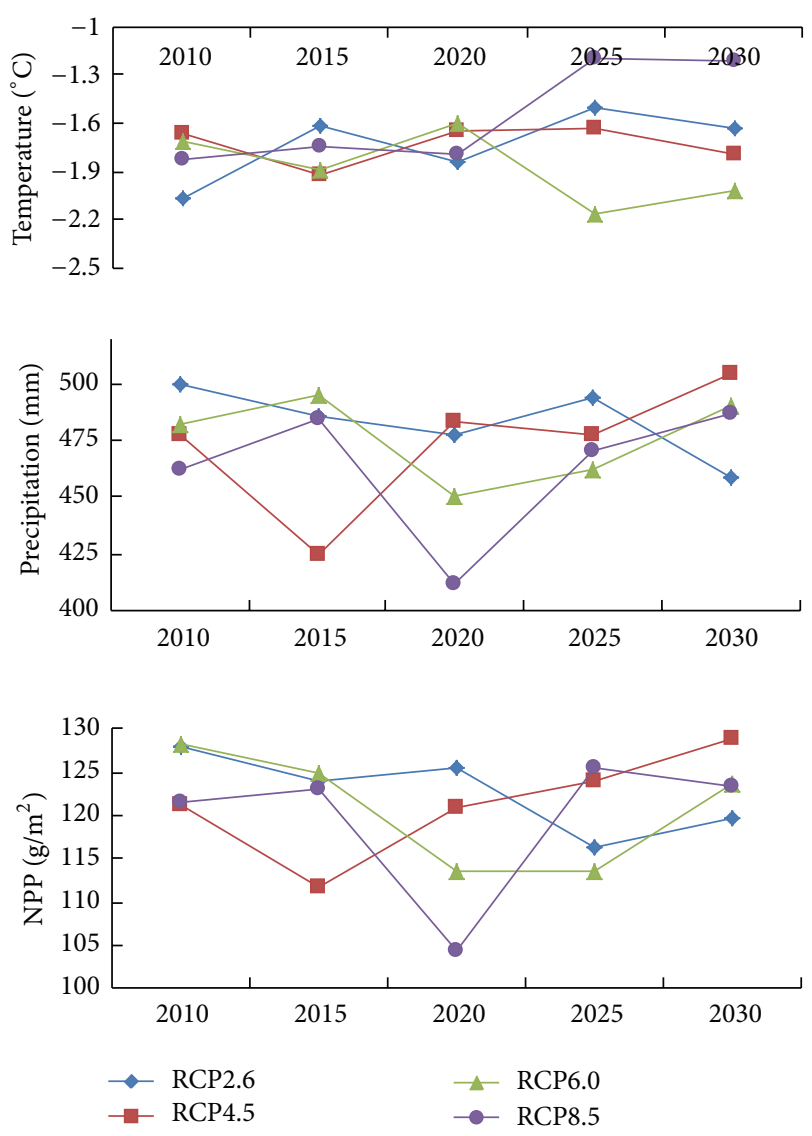

FIGURE 3: Changing trends of the NPP of grassland, temperature, and precipitation (the average number in every year) in the TRHR during 2010-2030.

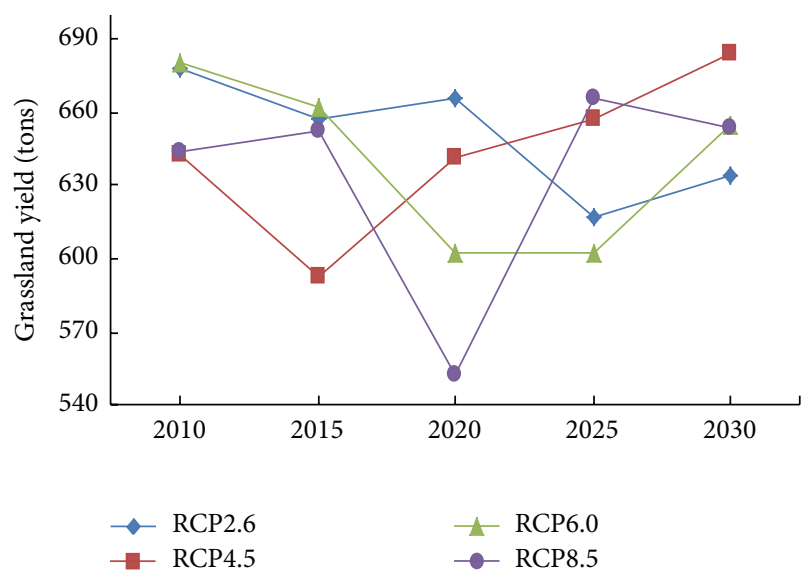

FIGURE 4: Changing trends of grass yield of grassland in the TRHR during 2010-2030 under the four scenarios.

comparison to the changing trend of NPP mentioned above, the changing trend of the grass yield is consistent with that of the NPP during 2015-2030, but they are not closely related during 2010-2015.

The result under the RCP6.0 scenario indicates that the grass yield will decline during 2010-2020 and then tends

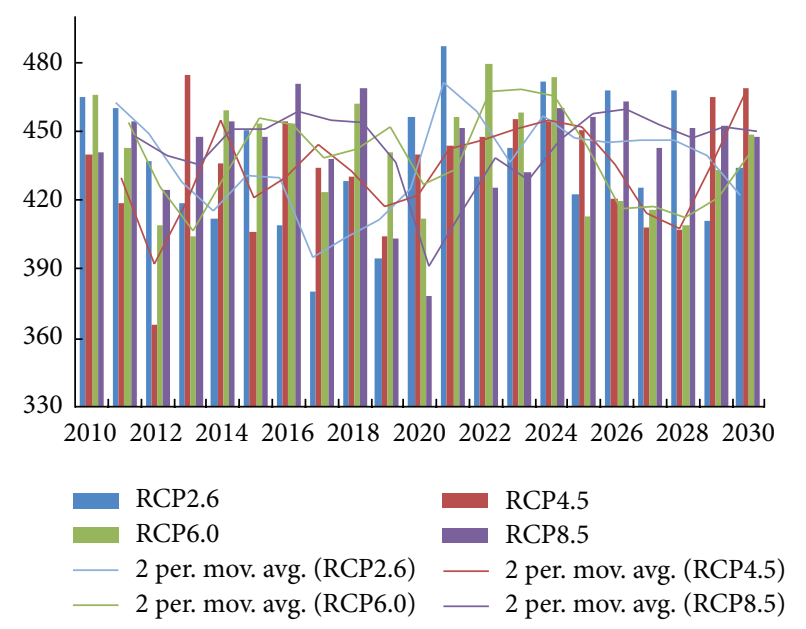

FIGURE 5: Theoretical grazing capacity in the TRHR during 20102030 (ten thousand sheep).

to increase slowly after reaching a low level around 2020, indicating that the grass yield of the TRHR will fluctuate greatly under this scenario.

The result under the RCP8.5 scenario suggests that the grass yield of the TRHR will fluctuate slightly during 20102015, then declines significantly, and thereafter keeps an increasing trend, but the increment will gradually decline and there may even be some slight decrease. According to the analysis above, it is predictable that the grass yield will fluctuate obviously around 2020 and decline to a very low level and will only fluctuate slightly during other periods under this scenario.

To sum up, there is a positive relationship between the grass yield and NPP of grassland in the TRHR. The change of the NPP of grassland has an impact on the grass yield, but its effects vary among different RCPs scenarios. The grass yield is very stable under the RCP2.6 scenario, generally above 6.3 million tons every year. Under the RCP4.5 and RCP6.0 scenarios, the changing trends of the grass yield and NPP of grassland are generally similar during most periods except for 2015-2020, during which their changing trends are contrary. Under the RCP8.5 scenario, the grass yield fluctuates most greatly, and the precipitation, grass yield, and NPP of grassland will all descend to the bottom around 2020, indicating that the grass yield is most greatly influenced by the precipitation under this scenario.

4.3. Analysis of the Grazing Capacity of Grassland. The theoretical grazing capacity during 2010-2030 was analyzed in this study. The grazing capacity of grassland in the TRHR was calculated on the basis of the grass yield. The result indicates that the theoretical grazing capacity ranges from 4 million sheep to 5 million sheep under the four scenarios (Figure 5).

The result under the RCP2.6 scenario indicates that the theoretical grazing capacity in the TRHR will show a significant decreasing trend and reach the minimum in 2017, and it will then increase rapidly during 2018-2021 but will thereafter keep a decline trend on the whole (Figure 5). Besides, 
the inter-annual fluctuation range is very great under this scenario. According to the changing trends of the temperature and precipitation mentioned above, the grazing capacity responds very slowly to the change of temperature within a certain scope and there is no significant relationship between them, while the grazing capacity shows a changing trend similar to that of the precipitation. The result indicates that, under the condition of no great fluctuation in the temperature, the grazing capacity mainly depends on the precipitation, which is consistent with the actual condition that the local animal husbandry is mainly restricted by the water resource.

The result under the RCP 4.5 scenario indicates that the grazing capacity fluctuates greatly during 2010-2015, but the fluctuation range will gradually decrease with the time. It shows an increasing trend during 2015-2025, especially during 2019-2025, and there will be a stable and continuous increase. The grazing capacity will first decrease sharply and then increase rapidly during 2025-2030. On the whole, the grazing capacity fluctuates very greatly and the stability is very low under this scenario. It suggests that the grazing capacity of the local grassland increases with the precipitation within a certain scope, beyond which the temperature will play a more important role. In comparison to the changing trends of the temperature and precipitation mentioned above, it can be seen that the influence of the temperature on the grazing capacity is always very significant under this scenario, while that of the precipitation is only significant during 20152025.

The result under the RCP6.0 scenario indicates that the grazing capacity shows a decreasing trend on the whole during 2010-2020, during which there is great fluctuation. The grazing capacity will first increase and then decrease during 2020-2030, and it shows a decreasing trend on the whole under this scenario. In comparison to the changing trends of the temperature and precipitation mentioned above, the changing trend of the grazing capacity is more consistent with that of the precipitation. However, during 2020-2030, the change of the grazing capacity is negatively related with the change of temperature, and it responds very slowly to the change of precipitation, and even not obviously. It indicates that the precipitation has more important impacts on the grazing capacity when the temperature is within a certain range; but on condition that the temperature decreases by a certain degree, the precipitation will only play a secondary role.

The result under the RCP8.0 scenario indicates that the local grazing capacity will fluctuate slightly during 20102015, but without significant change on the whole. It will continually decrease during 2016-2020 and reach the bottom around 2020 and then will keep increasing and finally fluctuate around 4.5 million sheep. According to the changing trends of the temperature and precipitation, the changing trend of the grazing capacity is more consistent with that of the precipitation, indicating that the precipitation plays a more important role on influencing the grazing capacity than the temperature does.

In summary, the precipitation plays a dominant role in influencing the grazing capacity under the RCP2.6 scenario, and the water resource is the main limiting factor of the development of the local animal husbandry. The precipitation has limited impacts on the development of the local animal husbandry under the RCP 4.5 scenario. The theoretical grazing capacity increases with the precipitation within a certain scope, beyond which the temperature will play a more important role. The precipitation and temperature both have some influence on the grazing capacity under the RCP6.0 scenario. The precipitation plays a more important role when the temperature reaches a certain scope and vice versa. The precipitation plays a more important role in influencing the grazing capacity under the RCP8.5 scenario. On the whole, the theoretical grazing capacity in the TRHR ranges from 4 million to 5 million sheep.

\section{Conclusion and Discussion}

This study estimated the NPP of grassland in the TRHR under four RCPs scenarios based on the comprehensive model and estimated the local grass yield and theoretical grazing capacity in the future. Besides, the future changing trends of the NPP, grass yield, and grazing capacity were analyzed under four scenarios. In this paper, we draw the following conclusions.

There are very complex influences of the precipitation and temperature on the grassland productivity, and the effects of the precipitation and temperature on the NPP, grass yield, and grazing capacity are very complex and unstable under different scenarios. For example, the theoretical grazing capacity in 2029 is 4.1072 million sheep under the RCP2.6 scenario, while it is 4.6527 million sheep under the RCP4.5 scenario, which also differs greatly under another two scenarios.

The grassland productivity in the TRHR is unstable on the whole. The grass yield is greatly influenced by the fluctuation of the precipitation and the temperature which also plays a more important role and subsequently influences the grazing capacity. This conclusion is consistent with that of the previous research on the changing trend of vegetation NPP in the past 50 years in the Yellow River Headwater Area, which was carried out by Yao et al. [36], indicating that the precipitation plays a dominant role in influencing the grassland productivity in the Three-River Headwaters region.

The grassland productivity in the TRHR will decrease slightly during 2010-2020, especially around 2020 when there will be a minimum, while the grazing capacity will first increase and then decrease during this period under all the scenarios except the RCP8.5 scenario. According to the analysis of the changing trend of the grazing capacity, there is a dramatic change in the grazing capacity in the TRHR due to the influence of the climatic factors. Therefore, it is necessary to reinforce the control on the grazing capacity, eliminate some livestock species in time, and replace the dominant grass species with the grass species that can better adapt to the climatic change. Besides, it is necessary to prepare for the various responses to the climatic change and formulate the artificial intervention mechanism as early as possible so as to reasonably guide the development of the local animal husbandry.

This study forecasted and analyzed the grassland NPP, hay yield of grasslands, and theoretical grazing capacity with 
the comprehensive model on the basis of the simulation of temperature and precipitation under the four scenarios. The research result is only obtained on the basis of the hydrothermal conditions, while in fact various factors, such as the soil, terrain, and solar radiation, all have some impacts on the grassland NPP. Therefore, there is still some limitations in the result of this study, and it is necessary to carry out more in-depth research works on the modification of the simulation result with the comprehensive model through including more other factors.

\section{Acknowledgments}

This research was supported by the National Basic Research Program of China (973 Program) (no. 012CB95570001) and China National Natural Science Funds for Distinguished Young Scholar (Grant no. 71225005), and the Exploratory Forefront Project for the Strategic Science Plan in IGSNRR, CAS are also appreciated.

\section{References}

[1] J. Liu, J. M. Chen, J. Cihlar, and W. Chen, "Net primary productivity distribution in the BOREAS region from a process model using satellite and surface data," Journal of Geophysical Research, vol. 104, no. 22, pp. 27735-27754, 1999.

[2] S. Piao, J. Fang, and J. He, "Variations in vegetation net primary production in the Qinghai-Xizang Plateau, China, from 1982 to 1999," Climatic Change, vol. 74, no. 1-3, pp. 253-267, 2006.

[3] G. Ren, J. Guo, and M. Xu, "Climate changes of China's mainland over the past half century," Acta Meteorologica Sinica, vol. 63, no. 6, pp. 942-956, 2005 (Chinese).

[4] H. Zuo and Y. Hu, "Variations trend of yearly mean air temperature and precipitation in China in the last 50 years," Plateau Meteorology, vol. 23, no. 2, pp. 238-244, 2004 (Chinese).

[5] Z. Wang, Y. Ding, and J. He, "An updating analysis of the climate change in China in recent 50 years," Acta Meteorologica Sinica, vol. 62, no. 2, pp. 228-236, 2004 (Chinese).

[6] China's National Climate Change Team, China Climate Change Country Study, Tsinghua University Press, 2000 (Chinese).

[7] F. Wu, X. Deng, F. Yin, and Y. Yuan, "Projected changes of grassland productivity along the representative concentration pathways during 2010-2050 in China," Advances in Meteorology, vol. 2013, Article ID 812723, 9 pages, 2013.

[8] X. Cui, Z. Chen, and Z. Du, "Study on and water-use characteristics of main plants in semiarid Steppe," Acta Prataculturae Sinica, vol. 10, no. 2, pp. 14-21, 2001 (Chinese).

[9] M. Cao, S. D. Prince, K. Li, B. Tao, J. Small, and X. Shao, "Response of terrestrial carbon uptake to climate interannual variability in China," Global Change Biology, vol. 9, no. 4, pp. 536-546, 2003.

[10] J. Fang, S. Piao, and C. B. Field, "Increasing net primary production in China from 1982 to 1999," Frontiers in Ecology and the Environment, vol. 1, no. 6, pp. 293-297, 2003.

[11] S. Piao, J. Fang, and Q. Guo, "Application of CASA model to the estimation of Chinese terrestrial net primary productivity," Acta Phytoecologica Sinica, no. 5, pp. 603-608, 2001 (Chinese).

[12] T. Xiao and J. Wang, "Vulnerability of grassland ecosystems in the Sanjiangyuan region based on NPP," Resources Science, vol. 32, no. 2, pp. 323-330, 2010 (Chinese).
[13] T. Xiao, J. Liu, and Q. Shao, "A simulation on changes in vegetation productivity in "Three River Sources" nature reserve, Qinghai province over past 20 years," Journal of Geo-Information Science, vol. 11, no. 5, pp. 558-564, 2009 (Chinese).

[14] J. Fan, Q. Shao, J. Wang, Z. Chen, and H. Zhong, "Analysis of temporal-spatial dynamics of grazing pressure on grassland in Three-River Headwaters region," Chinese Journal of Grassland, vol. 33, no. 3, pp. 64-70, 2011 (Chinese).

[15] J. Wang, J. Liu, Q. Shao, R. Liu, J. Fan, and Z. Chen, "SpatialTemporal patterns of net primary productivity for 1988-2004 based on Glopem-Cevsa model in the 'Three-River Headwaters' region of Qinghai province, China," Chinese Journal of Plant Ecology, vol. 33, no. 2, pp. 254-269, 2009.

[16] X. Xu, J. Liu, Q. Shao, and J. Fan, "The dynamic changes of ecosystem spatial pattern and structure in the Three-River Headwaters region in Qinghai province during recent 30 years," Geographical Research, vol. 27, no. 4, pp. 829-838, 2008 (Chinese).

[17] J. Zhan, X. Deng, and T. Yue, "Landscape change detection in Yulin prefecture," Journal of Geographical Sciences, vol. 14, no. 1, pp. 47-55, 2004.

[18] M. Gonzalez, M. Cariaga, and M. Skansi, "Some factors that influence seasonal precipitation in Argentinean Chao," Advances in Meteorology, vol. 2012, Article ID 359164, 13 pages, 2012.

[19] M. Zhang, W. Jiang, and Q. Chen, "Research progress in the estimation models of grassland net primary productivity," Acta Agrestia Sinica, vol. 19, no. 2, pp. 357-364, 2011 (Chinese).

[20] X. Deng, C. Zhao, and H. Yan, "Systematic modeling of impacts of land use and land cover changes on regional climate: a Review," Advances in Meteorology, vol. 2013, Article ID 317678, 11 pages, 2013.

[21] S. Shan, S. Zhou, J. Shi, and Y. Liu, "Calculation and comparison of vegetation net primary productivity (NPP) in Zhejiang province with three models," Chinese Journal of Agrometeorology, vol. 31, no. 2, pp. 271-276, 2010 (Chinese).

[22] C. Zhao, G. Chen, and S. Zhou, "Spatial distribution of the net primary productivity of natural vegetation in the northwest region," Journal of Lanzhou University, vol. 45, no. 1, pp. 42-49, 2009 (Chinese).

[23] Z. Li, Z. Liu, Z. Chen, and Z. Yang, "The effects climate changes on the productivity in the inner Mongolia steppe of China," Acta Prataculturae Sinica, vol. 12, no. 1, pp. 4-10, 2003 (Chinese).

[24] Editorial Board of Qinghai Vegetation, Qinghai People's Publishing House, 1994 (Chinese).

[25] Qinghai Grassland Station Qinghai Grassland Resource, Qinghai People's Publishing House, 1981 (Chinese).

[26] K. Wang, F. Hong, and J. Zong, "Resource resources and their sustainable utility in the "Three-River Headwaters" region," Acta Agrestia Sinica, vol. 13, pp. 28-311, 2005 (Chinese).

[27] G. Chen, X. Liu, M. Peng, and Y. Zhao, “The essential feature and protect of ecosystem in the Three-River Headwaters region of Qinghai province," Qinghai Science and Technology, vol. 4, pp. 14-171, 2003 (Chinese).

[28] G. Zhou and X. Zhang, "Study on NPP of natural vegetation in China under global climate change," Acta Phytoecologica Sinice, vol. 20, no. 1, pp. 11-19, 1996 (Chinese).

[29] G. Zhou and X. Zhang, "A natural vegetation NPP model," Acta Phytoecologica Sinica, vol. 19, no. 3, pp. 193-200, 1995 (Chinese).

[30] J. Gambiza and C. Nyama, Country Pasture/Forage Resource Profiles, FAO, 2006. 
[31] J. Yun, G. Liu, and S. Xu, "China’s terrestrial ecosystem carbon cycle and global significance".

[32] G. Wang and Y. Wen, Concentrations of Greenhouse Gases and Emissions Monitoring and Related Process, China Environmental Science Press, 1996 (Chinese).

[33] S. Piao, J. Fang, J. He, and Y. Xiao, "Spatial distribution of grassland biomass in China," Acta Phytoecologica Sinica, vol. 28, no. 4, pp. 491-498, 2004 (Chinese).

[34] B. Chen, China's Agricultural Resources Comprehensive Productivity and Population Carrying Capacity, China Meteorological Press, 2001 (Chinese).

[35] Y. Tian, Based on Grid of Chinese Terrestrial Ecosystem Food Function Evaluation, Graduate School of Chinese Academy of Sciences, 2005 (Chinese).

[36] Y. Yao, J. Yang, and G. Xiao, "Change feature of net primary productivity of natural vegetation and its impact factor in the source region of Yellow River in recent 50 years," Plateau Meteorology, vol. 30, no. 6, pp. 1594-1603, 2011 (Chinese). 

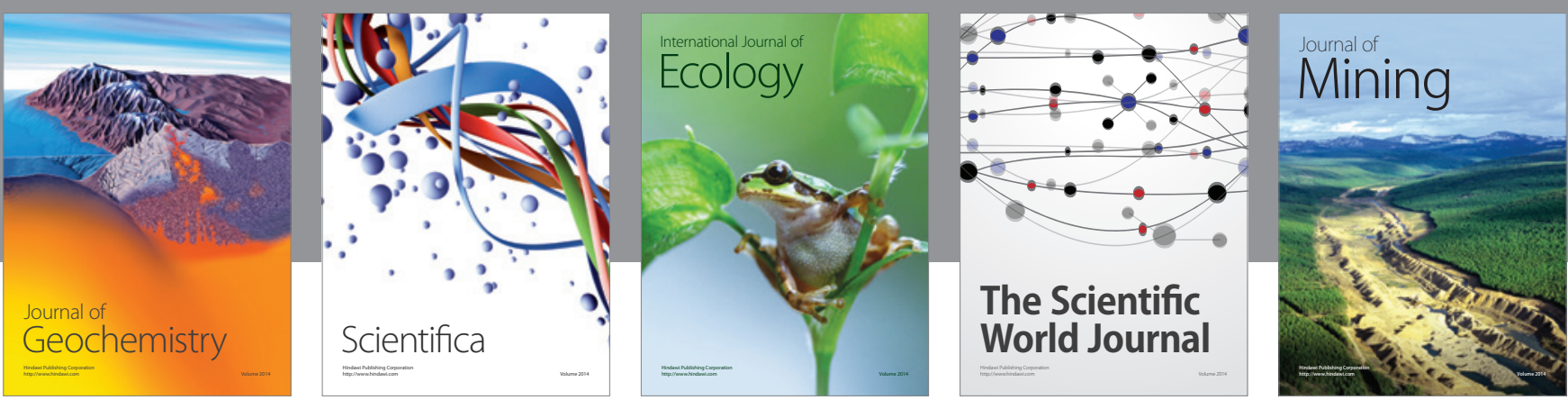

The Scientific World Journal
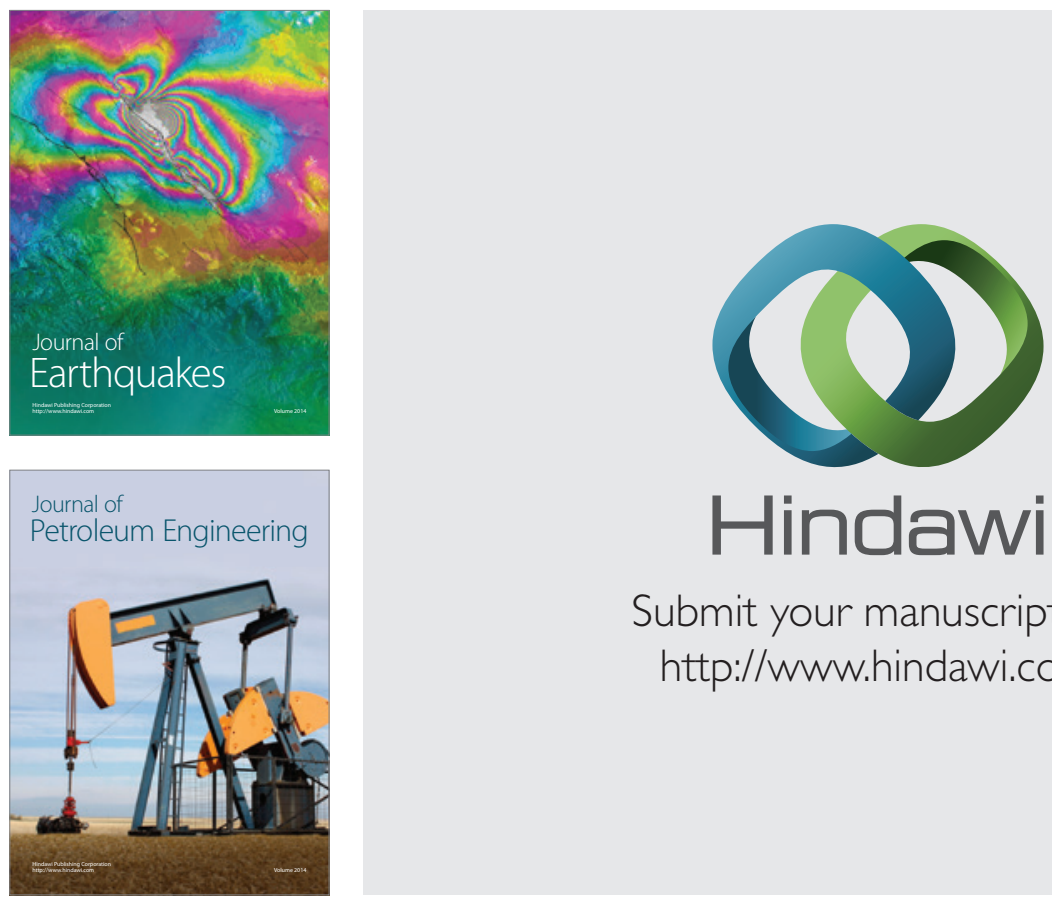

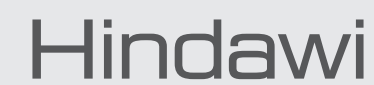

Submit your manuscripts at

http://www.hindawi.com
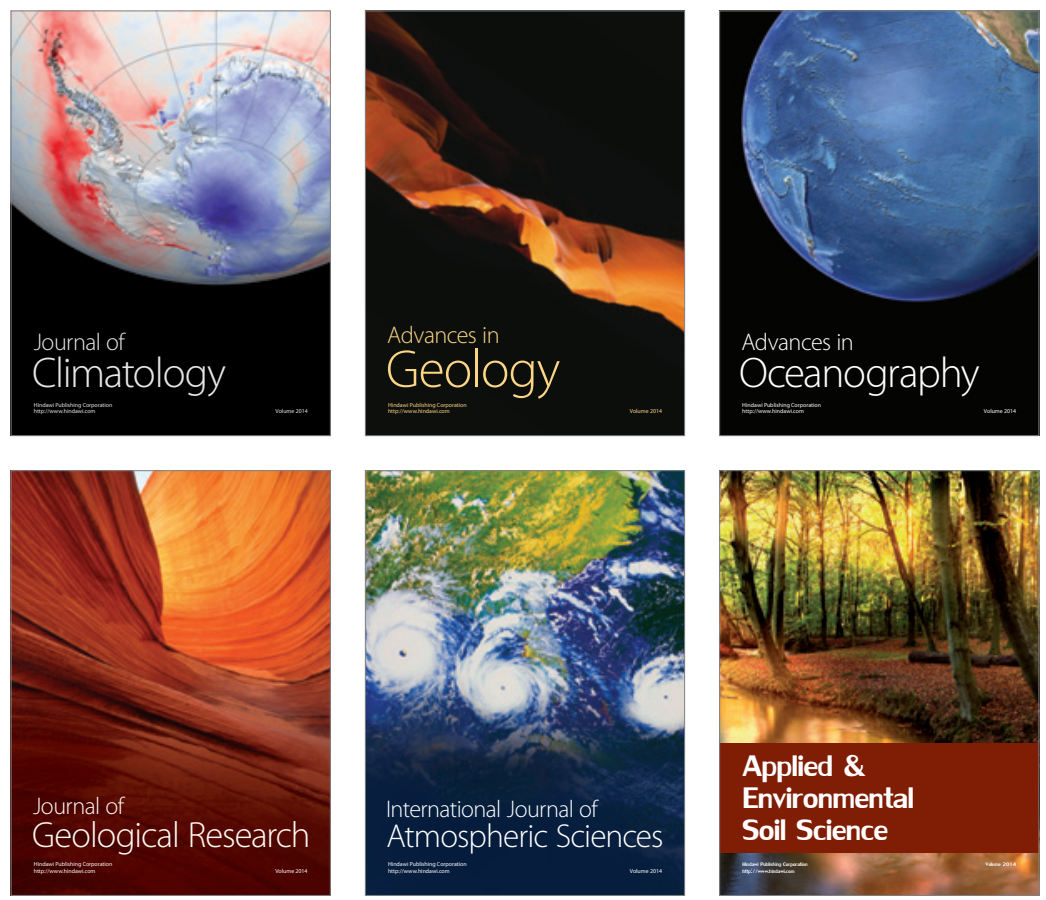
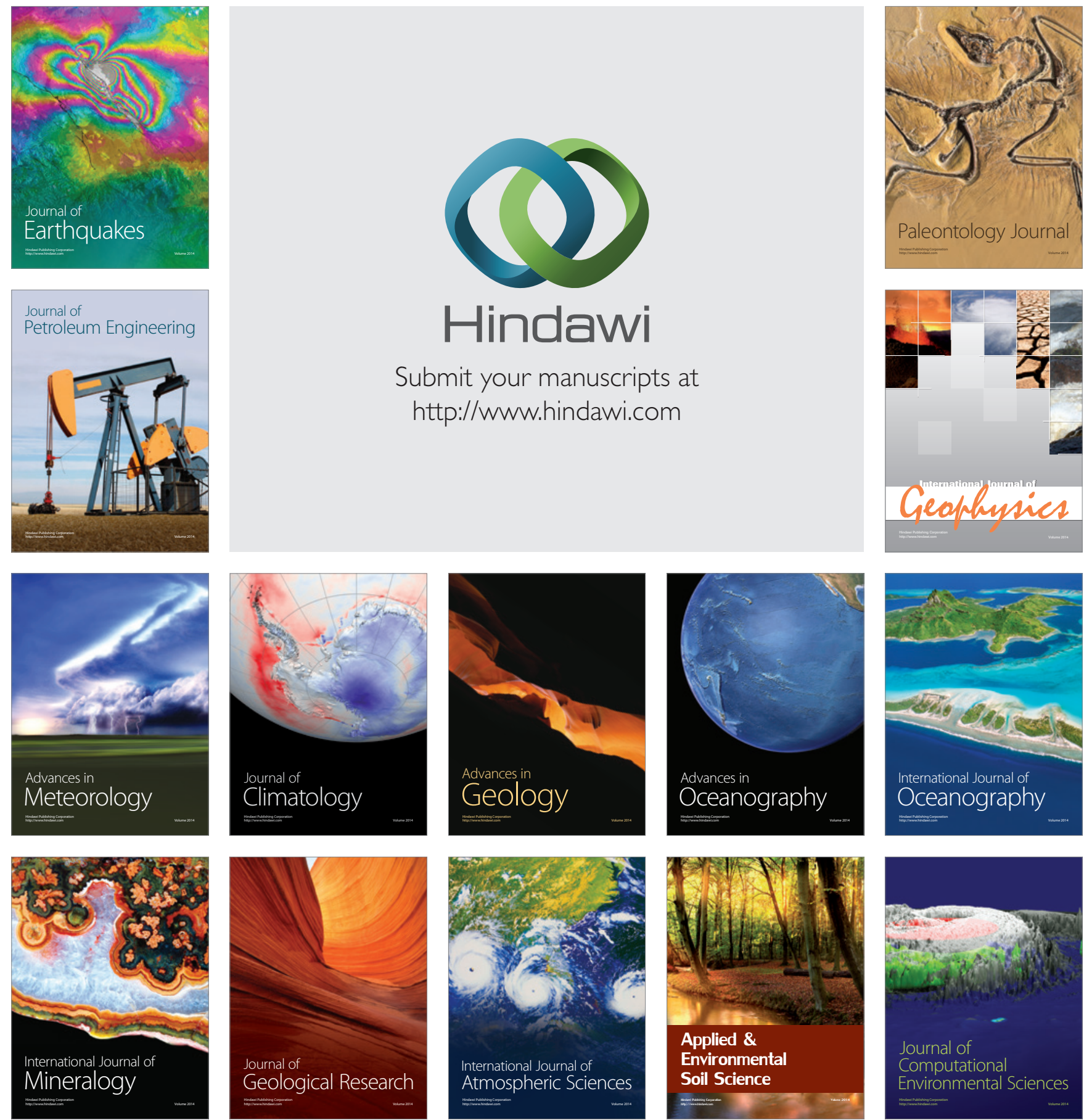